\title{
Critical Risk-Benefit Assessment of the Novel Anti-Cancer Aurora A Kinase Inhibitor Alisertib (MLN8237): A Comprehensive Review of the Clinical Data
}

\section{Abstract}

Background: Many current anticancer chemotherapeutics suffer from significant side effects, which have led to the exploration of more targeted therapies. This resulted in the exploration of inhibitors of Aurora A kinase as a potential anti-cancer treatment. Alisertib (MLN8237) has proven to be a potent Aurora A kinase inhibitor that had the highest safety profile among its therapeutic family. Phase I/II/III clinical trials with Alisertib have been carried out and reported promising efficacy, yet serious side effects. This article attempts to assess the clinical effect of Alisertib administration in various cancer phenotypes while describing the reported side effects.

Methods: Alisertib clinical data were systematically retrieved from Medline, CINAHL, PubMed, and Cochrane Central Register of Controlled Trials and analyzed for quality, relevance, and originality in three stages prior to inclusion.

Results: Overall, seven studies met inclusion criteria and enrolled a total of 630 patients. The reported “potential” clinical effect of Alisertib in various tumours is promising as it improved time to disease progression, progression-free survival, and the duration of disease stability. The achieved improvement therefore rationalizes its further investigation as a novel anticancer therapy. However, the administration of the drug was associated with serious haematological disturbances in a relatively high percentage of patients.

Conclusion: The evidence of the anti-tumour effect of Alisertib administration is compelling in various types of malignancies. The reported side effects were serious but manageable in many cases. Topical or more targeted routes of administration are suggested when possible to overcome off-target events with systematic administration of the drug.

\section{Keywords}

Chemotherapy complication, Alisertib, Aurora A Kinase, systematic review, risk-benefit assessment

\section{Introduction}

Cancer remains a major health priority area with the global burden increasing from 14.1 million in 2012 (1) to 14.9 million cases in 2013(2). Mortality rates were 8.2 million in these consecutive years $(1,2)$. On average, cancer claimed more than 22,000 lives daily throughout 2013(2). The significant burden of cancer suggests a flaw in the current strategies of treatment and probably, screening, prophylaxis, and the diagnostic procedures. However, other factors related to the increase in population and the lack of proper treatment in the developing countries may contribute as well. 
Current treatment practice includes surgery (3-5), chemotherapy (6) and radiotherapy (7) in the majority of the cases. Despite the efficacy of some treatments in early cancer stages, they are usually nonspecific in nature, associated with side effects on normal tissues and prone to develop resistance (8). Moreover, the accompanied harsh and invasive side effects of such treatments significantly affect the patient's quality of life, which may subsequently leave the patient susceptible to new cancers $(9,10)$. Therefore, there is a pressing need for the development of novel cancer treatments to improve the survival rates and decrease the burden of the disease.

Indeed, a range of new highly specific treatments have entered the market recently or are in clinical trial. Blocking angiogenesis from/in the tumour stroma (11), targeting specific oncogenic proteins and their subsequent inhibition of tumour suppressor factors (12) and targeting cell cycle regulators (13) are all strategies that have the potential to significantly increase the specificity and efficacy of cancer treatment (11-13).

In this paper, we examine the critical cell cycle regulator belonging to the Aurora Kinase family, Aurora A Kinase (AURKA) (14). AURKA, AURKB, and AURKC are involved in numerous cell cycle events including chromosome alignment, cytokinesis (15), centrosome function, and spindle formation, and assembly during the mitosis stage of cell cycle (16-18). AURKA also acts as a gate keeper for the G2-M check point in cell cycle and its deregulation was reported to induce G2-M arrest followed by apoptosis (19), in addition to severe mitotic abnormalities resulting in selective lethality for many types of solid and haematological malignancies $(20,21)$.

In addition to its mitotic roles, AURKA contributes to acquiring resistance to standard treatments through its non-mitotic functions. More specifically, AURKA provides cells with stem-like properties by transforming them from epithelial to mesenchymal type $(22,23)$. This transformation aids in potentiating the progression of the tumour, metastasising, and increasing the resistance towards treatments (23-25).

Interestingly, a growing body of literature has shown over-expression of AURKA in numerous types of cancers including colorectal, ovarian, gastric (21), and haematological cancers (20). This suggests that these types of cancers may be dependent on AURKA to survive (15, 26, 27). Due to its important roles in maintaining chromosomal integrity, cell cycle regulation, and its up-regulation in various types of tumour models, it was considered a strong potential candidate for anti-cancer targeted interventions.

Accordingly, many AURKA inhibitors were developed. During the last 10 years, more than 13 different inhibitors of the Aurora kinases have been tested in phase I clinical trials in patients with hematologic and solid tumours. The majority of these agents were inhibitors of all Aurora- $A,-B$, and $-C$ indiscriminately. However, only a few inhibitors made it through to phase II clinical trials. Several trials were suspended or not completed due to serious cytotoxic side effects observed upon administration of clinically effective doses, while others 
were discontinued due to inadequate anti-tumour ac tivity (28-30). Despite the fact that there were several proposed selective inhibitors for AURKA such as MLN 8054 (31), TAS-119 (22), MK-5108, ENMD-2076, and MLN 8237 (32), only MLN 8237 (also known as Alisertib) progressed to phase III evaluation (33). Alisertib was developed as a structurally improved generation of a previously established inhibitor, MLN 8054. The latter was the first AURKA inhibitor to be evaluated in human phase I clinical trial due to its encouraging pharmaceutical characteristics, such as reliable absorption and prolonged half-life in preclinical models. However, upon clinical administration, patients suffered from central nervous system (CNS) side effects due to its structural similarity to the benzodiazepine family, particularly somnolence due to GABAA $\alpha-1$ benzodiazepine off-targeting(34). Subsequently, a change in the structure of MLN 8054 led to the development of MLN 8237 (apyrimidobenzazepines), which showed less affinity to GABAA $\alpha-1$ and therefore, less CNS side effects (35).

In preclinical data, Alisertib has been able to achieve robust anti-tumour efficacy that rationalized its further advancement to clinical trials (36-41). Growth inhibition was achieved in a wide range of cell cultures, including cells originating from HTLV-1 infected adult T-cell leukemia (42), peripheral T-cell lymphomas (37), multiple myeloma (38), human tongue squamous cell carcinoma (39), malignant bladder cancer (40), and cervical cancer (36) cell lines. The latter were able to be completely cured in mouse xenograft models (36).

Despite its efficacy, its safety profile is still concerning. Severe drug-related side effects like neutropenia and anaemia were reported in Phase I/II clinical trials (43-52). Hence, this systematic review examines the therapeutic potential and safety profile of Alisertib from the publically data available.

\section{Methods}

This review was undertaken according to the PRISMA guideline for systematic reviews. All published human trials testing Alisertib for any cancer type were considered for inclusion with the most recent database search performed on 25 August 2016. Medline database via EBSCO HOST, CINAHL database via EBSCO HOST, PubMed and Cochrane Central Register of Controlled Trials were searched for articles using the terms [Alisertib OR mln8237 OR "MLN 8237" OR "mln-8237"] in the TITLE field. This was limited to human trials only in the last 10 years that are written in English. Articles from the authors' database and bibliographic references cited by original and review articles identified as part of the literature search were also explored and cross-referenced against the search results.

A design of inclusion criteria for this systematic review was generated to include the most robust clinical trials undertaken on adults in various types of cancer. The studies were analyzed in three stages prior to inclusion in the final review. To be included in this review, the article had to report both efficacy and side effects of Alisertib systematic administration in adult patients diagnosed with any type of cancer. Animal or basic science 
research articles, studies testing Alisertib in combination with other drugs, and studies that had less than 40 patients were excluded.

Duplicate articles were removed, followed by screening titles and abstracts as per the criteria previously outlined. The search strategy is outlined in Figure 1. The full text of the articles was retrieved and the methods were analyzed.

Quality Assessment Tool for Quantitative Studies was utilized to assess the quality of the included studies(53). Briefly, this tool addresses eight criteria (selection bias, study design, confounders, blinding, data collection methods, withdrawals and dropouts, intervention integrity, and analysis appropriate to question) to appraise study quality (table 2). The final global rating classifies studies into strong (no weak rating in all the eight areas), moderate (one weak rating), or weak (two or more weak ratings). Discrepancies in quality assessment were resolved by inviting an expert opinion.

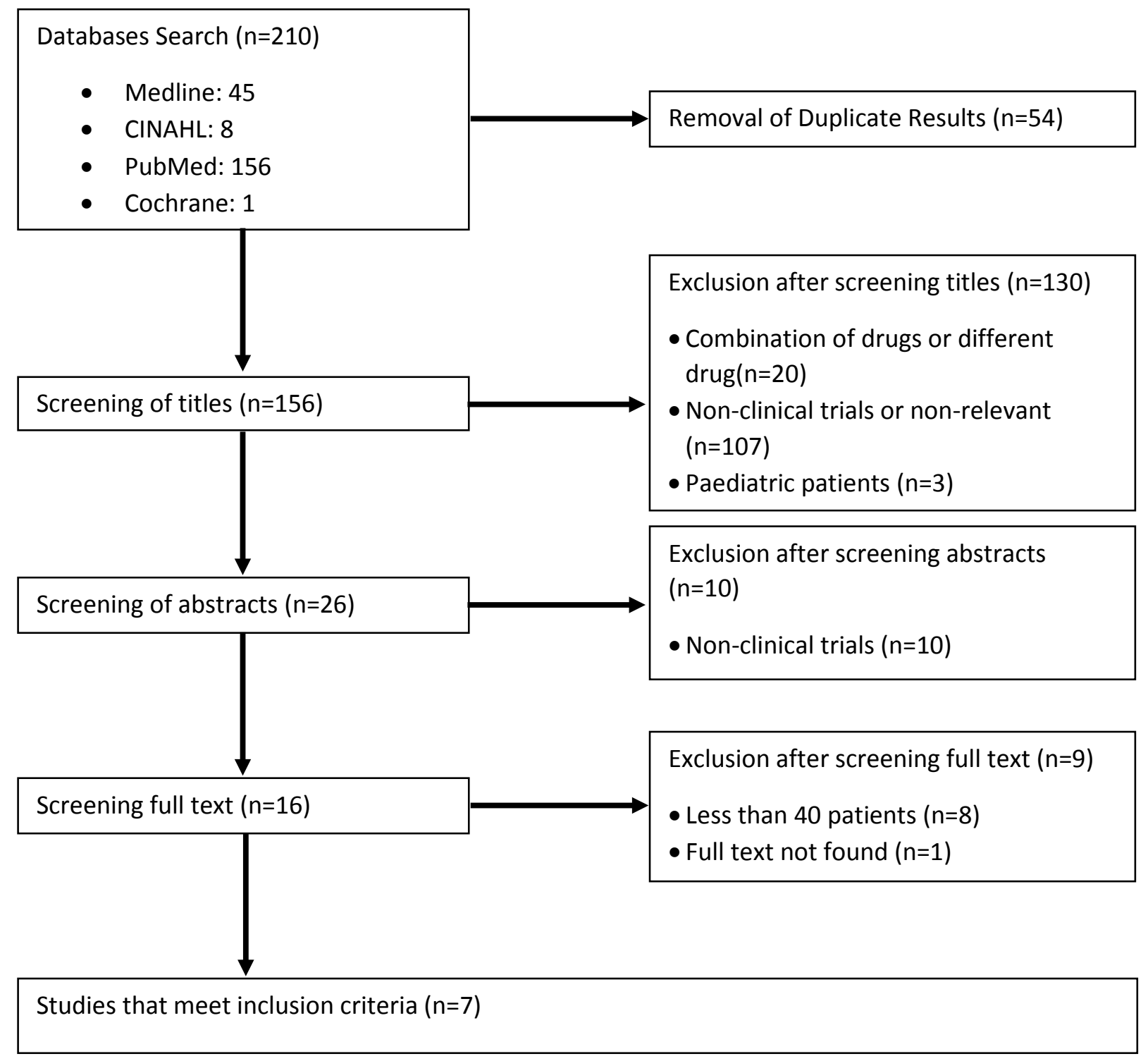


Figure 1. Study flow chart. Searching strategy and databases hits

\section{Results}

\subsection{Description of the included studies}

A total of 210 articles were identified following removal of duplicates and application of initial filters, with 16 articles nominated, and their methods were assessed in greater detail. That resulted in a further exclusion of nine articles and therefore, seven articles were included in this review for the final qualitative synthesis (table 1).

This comprised 3 phase I and 4 phase II clinical trials. These studies form the basis for the following analysis of efficacy and safety of Alisertib 
Table 1.Human trials included in the current systematic review after following the search strategy outlined in figure 1.PFS: progression-free survival, OS: overall survival, DOR: duration of response, RR: response rate, ORR: overall response rate PO: per oral, BID: twice a day, QD: once a day, d: day, PIC: powder-in-capsule, ECT: enteric-coated tablet. DLTs: dose-limiting toxicities, MTD: maximum tolerated dose, PK: pharmacokinetics, PD: pharmacodynamics

\begin{tabular}{|c|c|c|c|c|c|c|c|c|}
\hline \multirow[b]{2}{*}{ ID } & \multirow[b]{2}{*}{$\begin{array}{l}\text { Author } \\
\text { (year) }\end{array}$} & \multirow[b]{2}{*}{$\begin{array}{l}\text { Initial dose } \\
\text { (treatment/rest) }\end{array}$} & \multirow{2}{*}{$\begin{array}{l}\text { Primary } \\
\text { end } \\
\text { point(s) }\end{array}$} & \multirow[b]{2}{*}{$\begin{array}{l}\text { Secondary } \\
\text { end point(s) }\end{array}$} & \multicolumn{4}{|c|}{ Patient Characteristic } \\
\hline & & & & & $\mathrm{N}$ & $\begin{array}{l}\text { Age (y) } \\
\text { Med } \\
\text { (range) }\end{array}$ & $\begin{array}{l}\text { Male } \\
\%\end{array}$ & Cancer Type (\%) \\
\hline 1 & $\begin{array}{l}\text { Dickson et } \\
\quad \text { al } \\
\text { (2016) (54) }\end{array}$ & $\begin{array}{l}50 \text { mg PO BID } \\
(7 \mathrm{~d} / 14 \mathrm{~d})\end{array}$ & $\mathrm{RR}$ & $\begin{array}{l}\text { PFS } \\
\text { OS }\end{array}$ & 72 & $\begin{array}{c}54.5 \\
(20-84)\end{array}$ & 54 & $\begin{array}{l}\text { Liposarcoma (17), } \\
\text { Leiomyosarcoma (non-uterine) } \\
\text { (14), Undifferentiated sarcoma } \\
\text { (15), Malignant peripheral nerve } \\
\text { sheath tumour (14), Other (40) }\end{array}$ \\
\hline 2 & $\begin{array}{l}\text { Melicharet } \\
\quad \text { al } \\
\text { (2015) (55) }\end{array}$ & $\begin{array}{l}50 \text { mg PO BID } \\
(7 d / 14 d)\end{array}$ & $\mathrm{RR}$ & $\begin{array}{l}\text { DOR } \\
\text { Time to } \\
\text { progression } \\
\text { PFS }\end{array}$ & $\begin{array}{l}249^{1} \\
/ 212^{2}\end{array}$ & $\begin{array}{c}60.1^{3} \\
(49-73)\end{array}$ & $54.72^{2}$ & $\begin{array}{c}\text { Breast Cancer }(23)^{2} \text {,Small-cell } \\
\text { lung cancer }(23)^{2} \text {,Non-small-cell } \\
\text { lung cancer }(11)^{2} \text {, Head and neck } \\
\text { squamous-cell carcinoma }(21)^{2} \text {, } \\
\text { Gastro-esophageal } \\
\text { adenocarcinoma }(22)^{2}\end{array}$ \\
\hline 3 & $\begin{array}{l}\text { Kelly et al } \\
\text { (2014) (56) }\end{array}$ & $\begin{array}{c}\text { PIC: } \\
25 \text { or } 35 \text { mg/day }{ }^{4} \\
\text { BID d1, QD d2- } \\
14 \text { or } 21 \\
\text { (14d/14d or } \\
\text { 1d/7d) } \\
\text { ECT: } \\
\text { 40mg/day QD } \\
\text { (14d/28d) }\end{array}$ & $\begin{array}{l}\text { DLTs } \\
\text { MTD } \\
\text { PK }\end{array}$ & $\begin{array}{c}\text { RR } \\
\text { DOR } \\
\text { AAK } \\
\text { inhibition } \\
\text { Gene } \\
\text { amplification }\end{array}$ & 58 & $\begin{array}{c}61 \\
(27-82)\end{array}$ & 47 & $\begin{array}{l}\text { Non-Hodgkin lymphoma (62), } \\
\text { Multiple myeloma (33), Chronic } \\
\text { lymphocytic leukaemia/ small } \\
\text { lymphocytic leukaemia (5) }\end{array}$ \\
\hline 4 & $\begin{array}{c}\text { Friedberg et } \\
\text { al } \\
\text { (2014) (57) }\end{array}$ & $\begin{array}{l}50 \text { mg PO BID } \\
(7 d / 14 d)\end{array}$ & $\mathrm{RR}$ & $\begin{array}{c}\text { Safety } \\
\text { DOR } \\
\text { PFS } \\
\text { PK and PD }\end{array}$ & 48 & $\begin{array}{c}67.5 \\
(32-85)\end{array}$ & 73 & $\begin{array}{l}\text { B-cell lymphoma (83), Aggressive } \\
\text { T-cell lymphoma(17) }\end{array}$ \\
\hline 5 & $\begin{array}{c}\text { Goldberg et } \\
\text { al } \\
\text { (2014) (58) }\end{array}$ & $\begin{array}{l}50 \text { mg PO BID } \\
(7 \mathrm{~d} / 14 \mathrm{~d})\end{array}$ & ORR & $\begin{array}{l}\text { PFS } \\
\text { DOR }\end{array}$ & 57 & $\begin{array}{c}72 \\
(46-85)\end{array}$ & 56 & $\begin{array}{l}\text { Acute myelogenous leukaemia } \\
\text { (80.7), Myelodysplastic syndrome } \\
\text { (19.3) }\end{array}$ \\
\hline 6 & $\begin{array}{l}\text { Dees et al } \\
\text { (2012) (59) }\end{array}$ & $\begin{array}{l}\text { Various doses } \\
\text { tested }^{5} \\
(7 \mathrm{~d} / 14 \mathrm{~d}, 14 \mathrm{~d} / 14 \mathrm{~d} \\
\text { or } 21 \mathrm{~d} / 14 \mathrm{~d})\end{array}$ & $\begin{array}{l}\text { DLTs } \\
\text { MTD }\end{array}$ & $\begin{array}{c}\text { PK } \\
\text { AAK } \\
\text { inhibition } \\
\text { Bioavailability } \\
\text { Antitumor } \\
\text { activity }\end{array}$ & 87 & $\begin{array}{c}60 \\
(36-83)\end{array}$ & 51 & $\begin{array}{c}\text { Colorectal cancer (17), NSCLC } \\
\text { (11), Ovarian cancer (11) Soft } \\
\text { tissue sarcoma (9), Head and neck } \\
\text { cancer (7), Other (44) }\end{array}$ \\
\hline 7 & $\begin{array}{l}\text { Cervantes et } \\
\text { al (2012) } \\
\quad(60)\end{array}$ & $\begin{array}{l}\text { Various doses } \\
\text { tested }^{6} \\
\text { (7/14d) }\end{array}$ & $\begin{array}{l}\text { DLTs } \\
\text { MTD }\end{array}$ & $\begin{array}{c}\text { PK } \\
\text { AAK } \\
\text { inhibition } \\
\text { Antitumor } \\
\text { activity }\end{array}$ & 59 & $\begin{array}{c}61 \\
(30-78)\end{array}$ & 63 & $\begin{array}{l}\text { Colorectal cancer (46), Soft tissue } \\
\text { sarcoma (14), Head and neck } \\
\text { cancer (5), Ovarian cancer (5), } \\
\text { Renal cell carcinoma (5), Other } \\
\text { (25) }\end{array}$ \\
\hline
\end{tabular}

\footnotetext{
${ }^{1}$ Total number of patients

2 Patients assessable for response

${ }^{3}$ Patients assessable for response, Calculated as weighted median from all types of cancers

${ }^{4}$ Escalated to 45, 65, and then $90 \mathrm{mg}$ QD if dose-limiting toxicity were observed in no more than $0 / 3$ or $1 / 6$ patients.

${ }^{5}$ Ranged between 5-150 mg QD and between 40-60 mg BID

${ }^{6}$ Ranged between 5-150 mg QD and between 50-100 mg BID
} 


\subsection{Risk of bias assessment}

All the included studies were assessed according to the Quality Assessment Tool for Quantitative Studies. The results showed that all the included studies are of a "moderate" global rating. Given that all these studies were open-label phase I or II trials, blinding was not possible, and therefore all these studies were downgraded to a "moderate" quality (one weak rating in the blinding criterion). In addition, Melicharet al (2015) and Friedberg et al (2014) scored "moderate” in the withdrawal criterion as both studies reported a certain percentage of dropout due to side-effects or other reasons $(55,57)$.

Table 2: The quality assessment of the included studies

\begin{tabular}{|c|c|c|c|c|c|c|c|c|c|}
\hline Studies & 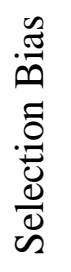 & 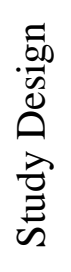 & 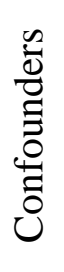 & 吕 & 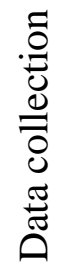 & 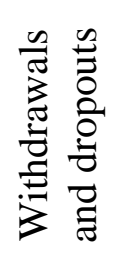 & 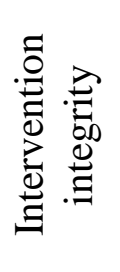 & 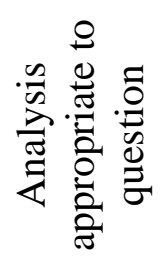 & $\begin{array}{l}.0 \\
.0 \\
0 \\
0 \\
0 \\
0 \\
0 \\
0\end{array}$ \\
\hline Dickson et al (2016) (54) & 2 & 2 & 1 & 3 & 1 & 1 & 1 & 1 & 2 \\
\hline Melicharet al (2015) (55) & 2 & 2 & 1 & 3 & 1 & 2 & 1 & 1 & 2 \\
\hline Kelly et al (2014) (56) & 2 & 2 & 1 & 3 & 1 & 1 & 1 & 1 & 2 \\
\hline Friedberg et al (2014) (57) & 2 & 2 & 1 & 3 & 1 & 2 & 1 & 1 & 2 \\
\hline Goldberg et al (2014) (58) & 2 & 2 & 1 & 3 & 1 & 1 & 1 & 1 & 2 \\
\hline Dees et al (2012) (59) & 2 & 2 & 1 & 3 & 1 & 1 & 1 & 1 & 2 \\
\hline Cervantes et al (2012) (60) & 2 & 2 & 2 & 3 & 1 & 1 & 1 & 1 & 2 \\
\hline
\end{tabular}

1: strong; 2: moderate; 3: weak.

\subsection{The anti-tumour activity of Alisertib administration in different types of malignancies}

In order to evaluate the clinical effect of Alisertib, various drug doses and formulations were tested in patients with advanced tumours. In most phase I or II trials, the clinical effect was described according to the evidence of Aurora A Kinase inhibition, achieving a clinical response (which was assessed by validated scales), time to disease progression, progression-free survival, and the duration of disease stability after the administration of Alisertib (55-59). Although the primary end-point in the included studies was to assess the toxicity and the safety of administration of Alisertib, and therefore they lacked a valid comparator for the purpose of efficacy assessment of the treatment, the reported improvement in the clinical response was promising. For example, a study by Melicharet al (2015), which utilized the revised version of Response Evaluation Criteria in Solid Tumours (RECIST) scale to assess the clinical response to treatment (61), reported a partial response rate of $18 \%$ in patients with breast cancer, and a $21 \%$ response rate in patients with small-cell lung cancer when Alisertib was administered in 21-day cycles, at a $50 \mathrm{mg}$ per dose, twice daily, for 7 days followed by a 14-day washout period (the mean duration of response was 5.6 and 4.1 months, respectively) (55). Similarly, Dees et al 
(2012) utilized the RECIST guidelines (the older version)(62), to assess the effect of this treatment on various, refractory to standard therapy, metastatic solid tumours, and reported a partial response rate of 23\%, which was sustained for more than 3 months (59). Alisertib treatment also seemed effective when administered to various haematological malignancies; with partial responses varying between 13\% and 27\% of the enrolled patients for at least 2 months (56-58). Goldberg et al (2014) described the requirement of multiple treatment cycles to demonstrate the anti-tumour effect of Alisertib (58). After four cycles, Alisertib treatment resulted in a median of 51 days of progression-free survival in patients diagnosed with acute myelogenous leukaemia (AML) (56). However, the effect of Alisertib is obviously disparate when administered in different types of malignancies. Even when given at the same dose and schedule, being $50 \mathrm{mg} /$ day twice daily for seven days followed by a 14day recovery, Alisertib administration showed modest effects in patients with non-small-cell lung cancer, head and neck squamous cell carcinoma and gastro-esophageal adenocarcinoma (55).Unlike patients with AML, Alisertib administration did not show any effect in patients with myelodysplastic syndromes (MDS) (58). One possible explanation is the difference in the pathogenesis between AML and MDS. The failure in the haematopoiesis in MDS is caused by increased apoptosis, rather than bone marrow suppression by proliferation as in AML. Thus, Alisertib administration may have been able to suppress abnormal proliferation in AML, but was not able to reverse apoptosis in MDS (58). Therefore, future investigation of the anti-tumour effect of Alisertib should take in consideration the tumour type and attempt to explain the mechanism of action of Alisertib in that specific context. Such understanding would certainly help to characterize more effective cancer therapeutics and deliver more patient-specific treatment options.

In addition, the anti-tumour activity of Alisertib was also assessed according to the inhibition of Aurora A Kinase in the skin and tumour specimens. Cervantes et al (2012) demonstrated an Alisertib-exposure-dependent increase in the number of mitotic cells with characteristic spindle abnormalities, which supported AURKA inhibition in tumour biopsies (60). Dees et al (2012) also collected skin biopsies pre-treatment and 6 and 24 hours after treatment. The results showed a significant increase in the mitotic cells in the basal epithelium following treatment, reflecting a consistent AURKA inhibition by Alisertib (59). However, one trial showed that the AURKA inhibition might not correlate with achieving a clinical response in some patients (56). The latter evidence highlights the possibility of a multi-factorial effect and the involvement of multiple molecular mechanisms to achieve a clinically quantifiable effect. In other words, the inhibition of AURKA per se may not be enough to achieve the desired anti-tumour effect in certain types of cancers.

Although the reported preclinical and clinical data on the effect of Alisertib in various malignancies seem exciting, such results should be interpreted with caution owing to several limitations in the design and reporting of these studies. Firstly, all the reported studies lacked a valid comparator, which means it is not possible to infer the causal relationship between the treatment and the observed clinical effect. Sure, as the included 
patients were end-of-life patients who failed every other therapy, it may not be ethical to include a valid control group at this stage (phase I or II trials), and the comparator was historical data, however, the findings of these trials should be described as a "potential” effect of Alisertib at best. Secondly, the exact mechanism of action of Alisertib should be thoroughly investigated in different cancer types. The fact that Alisertib exhibited an inconsistent effect across a range of different tumours sheds the light on the importance of mapping all the factors involved in the cancer development. Apart from assessing the effect of Alisertib on AURKA inhibition regardless of cancer phenotypes, it is perhaps helpful to also investigate its effect on other cancer-specific epigenetic/key oncogenes expression. Nevertheless, the reported “potential” clinical effect of Alisertib on various tumours is promising, and therefore rationalizes its further investigation as a novel anticancer therapy. Hence, many clinical trials are currently planned and recruiting patients.

\subsection{Safety assessment and its implications}

Phase I studies $(56,59,60)$ were mainly interested in determining dose-limiting toxicities (DLTs) and maximum tolerated dose (MTD) of Alisertib, and subsequently suggest a recommended phase II dose (RP2D) and treatment cycle. The three papers reported neutropenia as the highest frequent DLT, followed by other haematological side effects as leucopoenia, anaemia, and thrombocytopenia. Kelly et al (2014) suggested that administrating higher daily doses of Alisertib within shorter period of treatment (7d) is more tolerable than longer treatment cycles and will result in less frequent adverse events. Dees et al (2012) and Cervantes et al (2012) results aligned with this finding and therefore, they abandoned more than 7 days duration dosing schedules. It was also found that CNS side effects are related to high, once-daily dose, and dividing the dose into twice a day schedule decreased both the frequency and severity of these adverse events. Interestingly, 50 mg twice a day for 7 days of treatment followed by 14 days of recovery in a 21 day cycle was suggested by the three studies as RP2D.

Kelly et al (2012) and Dees et al (2012) were also interested in comparing two oral formulations of Alisertib, namely; powder in capsule (PIC) and enteric-coated tablets (ECT). Both studies reported similar bioavailability and pharmacokinetics properties for both PIC and ECT. However, Kelly et al (2012) suggested ECT for future development, as it allows Alisertib to bypass the acidity of the stomach and delay dissolution to the delivery site in the small intestine.

Overall, 630 patients were assessed in the seven studies. Only severe, life-threatening, and fatal adverse events (grade $\geq 3$ according to the National Cancer Institute's Common Terminology Criteria for Adverse Events (CTCAE)) related to the systematic administration of Alisertib were extracted individually from each study and summarized in table 3. 
Table 3. Most frequently reported drug-related grade $\geq \mathbf{3}$ adverse events in all papers (Papers ID as in table $\mathbf{1}$ ). All adverse events and serious adverse events were graded according to the National Cancer Institute's Common Terminology Criteria for Adverse Events (CTCAE), the values in the table represent $\mathrm{n}(\%)$ and is visually grouped according to the percentage of occurrence as follows: $1 \%-9 \%$, $10 \%-19 \%$ and $\geq 20 \%$

\begin{tabular}{|c|c|c|c|c|c|c|c|c|}
\hline $\begin{array}{c}\text { Study ID } \\
\text { (n) }\end{array}$ & $\begin{array}{c}1 \\
(n=72)\end{array}$ & $\begin{array}{c}2 \\
(n=249)\end{array}$ & $\begin{array}{c}3 \\
(n=58)\end{array}$ & $\begin{array}{c}4 \\
(n=48)\end{array}$ & $\begin{array}{c}5 \\
(n=57)\end{array}$ & $\begin{array}{c}6 \\
(n=87)\end{array}$ & $\begin{array}{c}7 \\
(n=59)\end{array}$ & $\begin{array}{c}\text { Total } \\
(n=630)\end{array}$ \\
\hline Neutropenia & $\begin{array}{c}30 \\
(42 \%)\end{array}$ & $\begin{array}{c}107 \\
(43 \%)\end{array}$ & $\begin{array}{c}26 \\
(45 \%)\end{array}$ & $\begin{array}{c}30 \\
(63 \%)\end{array}$ & $\begin{array}{c}7 \\
(12 \%)\end{array}$ & $\begin{array}{c}26 \\
(30 \%)\end{array}$ & $\begin{array}{c}20 \\
(34 \%)\end{array}$ & $\begin{array}{c}246 \\
(39 \%)\end{array}$ \\
\hline Leukopenia & $\begin{array}{c}16 \\
(22 \%)\end{array}$ & $\begin{array}{c}53 \\
(21 \%)\end{array}$ & $\begin{array}{c}14 \\
(24 \%)\end{array}$ & $\begin{array}{c}26 \\
(54 \%)\end{array}$ & $\begin{array}{c}2 \\
(4 \%) \\
\end{array}$ & & $\begin{array}{c}13 \\
(22 \%)\end{array}$ & $\begin{array}{c}124 \\
(20 \%)\end{array}$ \\
\hline Anaemia & $\begin{array}{c}10 \\
(14 \%) \\
\end{array}$ & $\begin{array}{c}26 \\
(10 \%) \\
\end{array}$ & $\begin{array}{c}11 \\
(19 \%)\end{array}$ & $\begin{array}{c}17 \\
(35 \%)\end{array}$ & $\begin{array}{c}5 \\
(9 \%) \\
\end{array}$ & $\begin{array}{c}7 \\
(8 \%) \\
\end{array}$ & $\begin{array}{c}6 \\
(10 \%) \\
\end{array}$ & $\begin{array}{r}82 \\
(13 \%) \\
\end{array}$ \\
\hline Thrombocytopenia & $\begin{array}{c}10 \\
(14 \%) \\
\end{array}$ & $\begin{array}{c}18 \\
(7 \%) \\
\end{array}$ & $\begin{array}{c}16 \\
(28 \%)\end{array}$ & $\begin{array}{c}16 \\
(33 \%)\end{array}$ & $\begin{array}{c}5 \\
(9 \%) \\
\end{array}$ & $\begin{array}{c}5 \\
(6 \%) \\
\end{array}$ & $\begin{array}{c}7 \\
(12 \%) \\
\end{array}$ & $\begin{array}{c}77 \\
(12 \%) \\
\end{array}$ \\
\hline $\begin{array}{c}\text { Fatigue and } \\
\text { Asthenia }\end{array}$ & $\begin{array}{c}3 \\
(4 \%) \\
\end{array}$ & $\begin{array}{c}15 \\
(6 \%) \\
\end{array}$ & $\begin{array}{c}2 \\
(3 \%) \\
\end{array}$ & $\begin{array}{c}4 \\
(8 \%) \\
\end{array}$ & $\begin{array}{c}7 \\
(12 \%) \\
\end{array}$ & $\begin{array}{c}3 \\
(3 \%) \\
\end{array}$ & & $\begin{array}{c}34 \\
(5 \%) \\
\end{array}$ \\
\hline Stomatitis & & $\begin{array}{c}19 \\
(8 \%) \\
\end{array}$ & $\begin{array}{c}1 \\
(2 \%) \\
\end{array}$ & $\begin{array}{c}7 \\
(15 \%) \\
\end{array}$ & $\begin{array}{c}2 \\
(4 \%) \\
\end{array}$ & $\begin{array}{c}1 \\
(1 \%) \\
\end{array}$ & $\begin{array}{c}4 \\
(7 \%) \\
\end{array}$ & $\begin{array}{c}34 \\
(5 \%) \\
\end{array}$ \\
\hline Febrile neutropenia & $\begin{array}{c}7 \\
(10 \%) \\
\end{array}$ & & $\begin{array}{c}5 \\
(9 \%) \\
\end{array}$ & $\begin{array}{c}6 \\
(13 \%) \\
\end{array}$ & $\begin{array}{c}6 \\
(11 \%) \\
\end{array}$ & $\begin{array}{c}7 \\
(8 \%) \\
\end{array}$ & & $\begin{array}{c}31 \\
(5 \%) \\
\end{array}$ \\
\hline Lymphopenia & $\begin{array}{c}7 \\
(10 \%) \\
\end{array}$ & & $\begin{array}{c}4 \\
(7 \%) \\
\end{array}$ & $\begin{array}{c}2 \\
(4 \%) \\
\end{array}$ & & & $\begin{array}{c}4 \\
(7 \%) \\
\end{array}$ & $\begin{array}{c}17 \\
(3 \%) \\
\end{array}$ \\
\hline Diarrhea & $\begin{array}{c}1 \\
(1 \%)\end{array}$ & $\begin{array}{c}3 \\
(1 \%) \\
\end{array}$ & $\begin{array}{c}1 \\
(2 \%) \\
\end{array}$ & $\begin{array}{c}1 \\
(2 \%) \\
\end{array}$ & $\begin{array}{c}1 \\
(2 \%) \\
\end{array}$ & $\begin{array}{c}6 \\
(7 \%) \\
\end{array}$ & & $\begin{array}{c}13 \\
(2 \%) \\
\end{array}$ \\
\hline Mucositis oral & $\begin{array}{c}9 \\
(12 \%) \\
\end{array}$ & & & & & & & $\begin{array}{c}9 \\
(1 \%) \\
\end{array}$ \\
\hline Somnolence & & $\begin{array}{c}3 \\
(1 \%) \\
\end{array}$ & & $\begin{array}{c}1 \\
(2 \%) \\
\end{array}$ & $\begin{array}{c}2 \\
(4 \%) \\
\end{array}$ & $\begin{array}{c}2 \\
(2 \%) \\
\end{array}$ & & $\begin{array}{c}8 \\
(1 \%) \\
\end{array}$ \\
\hline Nausea & $\begin{array}{c}2 \\
(3 \%) \\
\end{array}$ & $\begin{array}{c}2 \\
(1 \%) \\
\end{array}$ & & $\begin{array}{c}1 \\
(2 \%) \\
\end{array}$ & & $\begin{array}{c}1 \\
(1 \%) \\
\end{array}$ & & $\begin{array}{c}6 \\
(1 \%) \\
\end{array}$ \\
\hline Vomiting & $\begin{array}{c}1 \\
(1 \%) \\
\end{array}$ & $\begin{array}{c}3 \\
(1 \%) \\
\end{array}$ & & & & $\begin{array}{c}1 \\
(1 \%) \\
\end{array}$ & & $\begin{array}{c}5 \\
(1 \%) \\
\end{array}$ \\
\hline $\begin{array}{c}\text { Palmar-Plantar } \\
\text { Erythrodysesthesia } \\
\text { Syndrome }\end{array}$ & $\begin{array}{c}3 \\
(4 \%)\end{array}$ & & & & & & & $\begin{array}{c}3 \\
(<1 \%)\end{array}$ \\
\hline Pneumonia & & & & $\begin{array}{c}3 \\
(6 \%) \\
\end{array}$ & & & & $\begin{array}{c}3 \\
(<1 \%) \\
\end{array}$ \\
\hline Pancytopenia & & & & $\begin{array}{c}3 \\
(6 \%) \\
\end{array}$ & & & & $\begin{array}{c}3 \\
(<1 \%) \\
\end{array}$ \\
\hline Sepsis & $\begin{array}{c}1 \\
(1 \%) \\
\end{array}$ & & & & $\begin{array}{c}1 \\
(2 \%) \\
\end{array}$ & & & $\begin{array}{c}2 \\
(<1 \%) \\
\end{array}$ \\
\hline Decreased Appetite & & $\begin{array}{c}1 \\
(1 \%) \\
\end{array}$ & & $\begin{array}{c}1 \\
(2 \%) \\
\end{array}$ & & & & $\begin{array}{c}2 \\
(<1 \%)\end{array}$ \\
\hline Dehydration & & & & $\begin{array}{c}2 \\
(4 \%) \\
\end{array}$ & & & & $\begin{array}{c}2 \\
(<1 \%) \\
\end{array}$ \\
\hline Leukocytosis & $\begin{array}{c}1 \\
(1 \%) \\
\end{array}$ & & & & & & & $\begin{array}{c}1 \\
(<1 \%) \\
\end{array}$ \\
\hline Anal mucositis & $\begin{array}{c}1 \\
(1 \%)\end{array}$ & & & & & & & $\begin{array}{c}1 \\
(<1 \%)\end{array}$ \\
\hline Typhlitis & $\begin{array}{c}1 \\
(1 \%)\end{array}$ & & & & & & & $\begin{array}{c}1 \\
(<1 \%)\end{array}$ \\
\hline
\end{tabular}




\begin{tabular}{|c|c|c|c|}
\hline Lung infection & $\begin{array}{c}1 \\
(1 \%) \\
\end{array}$ & & $\begin{array}{c}1 \\
(<1 \%)\end{array}$ \\
\hline $\begin{array}{c}\text { Alanine } \\
\text { aminotransferase } \\
\text { increased }\end{array}$ & $\begin{array}{c}1 \\
(1 \%)\end{array}$ & & $\begin{array}{c}1 \\
(<1 \%)\end{array}$ \\
\hline $\begin{array}{c}\text { Aspartate } \\
\text { aminotransferase } \\
\text { increased }\end{array}$ & $\begin{array}{c}1 \\
(1 \%)\end{array}$ & & $\begin{array}{c}1 \\
(<1 \%)\end{array}$ \\
\hline $\begin{array}{c}\text { Skin and } \\
\text { subcutaneous tissue } \\
\text { disorder }\end{array}$ & $\begin{array}{c}1 \\
(1 \%)\end{array}$ & & $\begin{array}{c}1 \\
(<1 \%)\end{array}$ \\
\hline Hypertension & $\begin{array}{c}1 \\
(1 \%) \\
\end{array}$ & & $\begin{array}{c}1 \\
(<1 \%)\end{array}$ \\
\hline Confusion & & $\begin{array}{c}1 \\
(2 \%) \\
\end{array}$ & $\begin{array}{c}1 \\
(<1 \%)\end{array}$ \\
\hline Dyspnoea & & $\begin{array}{c}1 \\
(2 \%)\end{array}$ & $\begin{array}{c}1 \\
(<1 \%)\end{array}$ \\
\hline
\end{tabular}

The single most obvious observation from the safety data was the haematological disturbance in a relatively high percentage of the patients, which aligns with the characteristics of cytotoxic agents (63). On top of the list, severe neutropenia occurred in 246 (39\%) patients, followed by leucopoenia, which was reported in 124 (20\%) patients. Severe anaemia and thrombocytopenia were also reported in $13 \%$ and $12 \%$ of the patients, respectively. Less frequent severe side effects included fatigue, stomatitis and febrile neutropenia and were reported in $5 \%$ of the total number of patients.

\section{Discussion and Conclusions}

Although it might be too early to make conclusions based on phase I/II trials, the evidence of the anti-tumour effect of Alisertib administration is compelling in various types of malignancies. Nevertheless, such treatment is associated with several serious side effects that might limit its future clinical use. However, several considerations should be seriously taken while assessing the efficacy/safety profile of Alisertib administration as an anticancer therapy. First, the reported heterogeneity of its clinical effects in different cancer types raises a red flag that Alisertib works differently in different disease contexts. Understanding the mechanism of action of Alisertib in different malignancies is therefore critical to mitigate or precisely profile potential life-threatening side effects. Moreover, it may not be wise to evaluate the efficacy/safety profile of Alisertib treatment in a group of patients with different types of malignancies. It is understandable that testing a new therapeutic molecule can be challenging in terms of recruiting patients and obtaining the ethical approval. However, segregating patients based on the cancer phenotype would represent the effect of Alisertib in a more precise way. From a statistical point of view, and given that most cancers are drastically different in terms of the pathogenesis and the molecular interactions involved in the cancer development, combining the effect of Alisertib administration on different types of cancer would be similar to comparing apples to oranges(64). 
Certainly, the total effect size from such studies might over-estimate or under-estimate the actual effect of Alisertib.

In addition, one study reported that the clinical effect of Alisertib administration did not necessarily correlate with AURKA inhibition (56). That has to say, the molecular changes being induced by Alisertib may not necessarily result in an anti-tumour effect. This finding implicates the involvement of other, more prominent, molecular pathways that determine the outcome of cancer. If this is the case, the analysis of other key cancer drivers while administering Alisertib treatment is imperative to evaluate to what extent such a treatment would impact the inter-pathway interactions and networking. Since the first mention of the oncogene-addiction theory (65), it has become evident that many cancer types depend on the continuous expression of certain genes to survive, and therefore many important gene-gene interactions were characterized as key drivers of carcinogenesis(66). While the included papers have only focused on the inhibition of AURKA as the primary indicator of Alisertib action, it would be worthwhile to also investigate its effect on other well-described key pathways.

More importantly, the safety profile of the systemic administration of Alisertib is worrisome as it needs careful dose scheduling and considerable washout periods. Given its cytotoxic nature, one should expect that Alisertib would cause these serious side effects. Therefore, exploring alternative routes of administration when possible can be the answer. Cervical cancer is an example, knowing that inhibiting Aurora A kinase was established as a strong potential target in this cancer (36), intravaginal delivery systems are therefore a recommended alternative. Indeed, local delivery systems have proven effective in reducing the serious side-effects associated with chemotherapeutics through avoiding systemic uptake and retention of these toxic agents in healthy tissues (67). Such systems can be exploited to deliver Alisertib to the site of interest with minimal systemic exposure, and thus help to reduce its side effects. 


\section{References}

1. de Martel C, Ferlay J, Franceschi S, Vignat J, Bray F, Forman D, et al. Global burden of cancers attributable to infections in 2008: a review and synthetic analysis. The LancetOncology. 2012;13(6):607-15.

2. Fitzmaurice C, Dicker D, Pain A, Hamavid H, Moradi-Lakeh M, Maclntyre MF, et al. The Global Burden of Cancer 2013. JAMA oncology. 2015;1(4):505-27.

3. Campana JP, Meyers AD. The Surgical Management of Oral Cancer. Otolaryngologic Clinics of North America. 2006;39(2):331-48.

4. Lachance JA, Darus CJ, Rice LW. Surgical Management and Postoperative Treatment of Endometrial Carcinoma. Reviews in Obstetrics and Gynecology. 2008;1(3):97-105.

5. Ruiterkamp J, Ernst MF. The role of surgery in metastatic breast cancer. European Journal of Cancer. 2011;47:S6S22.

6. Dasari S, Tchounwou PB. Cisplatin in cancer therapy: molecular mechanisms of action. European journal of pharmacology. 2014;0:364-78.

7. Baskar R, Lee KA, Yeo R, Yeoh K-W. Cancer and Radiation Therapy: Current Advances and Future Directions. International Journal of Medical Sciences. 2012;9(3):193-9.

8. Price KAR, Cohen EE. Current Treatment Options for Metastatic Head and Neck Cancer. Current Treatment Options in Oncology. 2012;13(1):35-46.

9. Savard J, Ivers H, Savard MH, Morin CM. Cancer treatments and their side effects are associated with aggravation of insomnia: Results of a longitudinal study. Cancer. 2015;121(10):1703-11.

10. Mustian KM, Devine K, Ryan JL, Janelsins MC, Sprod LK, Peppone LJ, et al. Treatment of Nausea and Vomiting During Chemotherapy. US oncology \& hematology. 2011;7(2):91-7.

11. Ochiya T, Takenaga K, Asagiri M, Nakano K, Satoh H, Watanabe T, et al. Efficient inhibition of tumor angiogenesis and growth by a synthetic peptide blocking S100A4-methionine aminopeptidase 2 interaction. Molecular Therapy Methods \& Clinical Development. 2015;2:15008.

12. Singhania R, Khairuddin N, Clarke D, McMillan NA. RNA interference for the treatment of papillomavirus disease. The open virology journal. 2012;6:204-15.

13. Aleem E, Arceci RJ. Targeting cell cycle regulators in hematologic malignancies. Frontiers in Cell and Developmental Biology. 2015;3(16).

14. Cheung $\mathrm{CH}$, Coumar MS, Hsieh HP, Chang JY. Aurora kinase inhibitors in preclinical and clinical testing. Expert opinion on investigational drugs. 2009;18(4):379-98.

15. Fu J, Bian M, Jiang Q, Zhang $\mathrm{C}$. Roles of Aurora kinases in mitosis and tumorigenesis. Molecular cancer research : MCR. 2007;5(1):1-10.

16. Perez Fidalgo JA, Roda D, Rosello S, Rodriguez-Braun E, Cervantes A. Aurora kinase inhibitors: a new class of drugs targeting the regulatory mitotic system. Clinical \& translational oncology : official publication of the Federation of Spanish Oncology Societies and of the National Cancer Institute of Mexico. 2009;11(12):787-98.

17. Gautschi O, Heighway J, Mack PC, Purnell PR, Lara PN, Jr., Gandara DR. Aurora kinases as anticancer drug targets. Clinical cancer research : an official journal of the American Association for Cancer Research. 2008;14(6):1639-

48.

18. Malumbres M, Perez de Castro I. Aurora kinase A inhibitors: promising agents in antitumoral therapy. Expert opinion on therapeutic targets. 2014;18(12):1377-93.

19. Du J, Hannon GJ. Suppression of p160ROCK bypasses cell cycle arrest after Aurora-A/STK15 depletion.

Proceedings of the National Academy of Sciences of the United States of America. 2004;101(24):8975-80.

20. Blagg J, Linardopoulos S, Moore AS, Pearson ADJ. Aurora kinase inhibitors: novel small molecules with promising activity in acute myeloid and Philadelphia-positive leukemias. Leukemia. 2010;24:671+.

21. Harrington EA, Bebbington D, Moore J, Rasmussen RK, Ajose-Adeogun AO, Nakayama T, et al. VX-680, a potent and selective small-molecule inhibitor of the Aurora kinases, suppresses tumor growth in vivo. Nature medicine.

2004;10(3):262-7.

22. Miura A, Sootome H, Ishihara K, Masuko N, Hirai H, Utsugi T. Abstract A268: TAS-119, a selective Aurora A inhibitor, enhanced the antitumor efficacy of taxanes in multiple human tumor cell lines including paclitaxel-resistant cells. Molecular cancer therapeutics. 2013;12(11 Supplement):A268-A. 
23. Regan JL, Sourisseau T, Soady K, Kendrick H, McCarthy A, Tang C, et al. Aurora A kinase regulates mammary epithelial cell fate by determining mitotic spindle orientation in a Notch-dependent manner. Cell reports. 2013;4(1):11023.

24. D'Assoro AB, liu T, Quatraro C, Amato A, Opyrchal M, Leontovich A, et al. The mitotic kinase Aurora-A promotes distant metastases by inducing epithelial-to-mesenchymal transition in $E R \alpha(+)$ breast cancer cells. Oncogene. 2014;33(5):599-610.

25. Opyrchal M, Sangameswaran KDG, Khoury T, Boland P, Galanis E, Haddad TC, et al. Aurora kinase inhibitors in breast cancer treatment. American Journal of Hematology/Oncology ${ }^{\circledR} .2015 ; 11(12)$.

26. Kops GJ, Weaver BA, Cleveland DW. On the road to cancer: aneuploidy and the mitotic checkpoint. Nature reviews Cancer. 2005;5(10):773-85.

27. Anand S, Penrhyn-Lowe S, Venkitaraman AR. AURORA-A amplification overrides the mitotic spindle assembly checkpoint, inducing resistance to Taxol. Cancer cell. 2003;3(1):51-62.

28. D'Assoro AB, Haddad T, Galanis E. Aurora-A Kinase as a Promising Therapeutic Target in Cancer. Frontiers in Oncology. 2015;5:295.

29. Jones S, Burris III H, Dumez H, Infante J, Fowst C, Gerletti P, et al., editors. Phase I accelerated dose-escalation, pharmacokinetic (PK) and pharmacodynamic study of PF-03814735, an oral aurora kinase inhibitor, in patients with advanced solid tumors: Preliminary results. ASCO Annual Meeting Proceedings; 2008.

30. Cohen R, Jones S, Von Mehren M, Cheng J, Spiegel D, Laffranchi B, et al., editors. Phase I study of the pan aurora kinases (AKs) inhibitor PHA-739358 administered as a $24 \mathrm{~h}$ infusion without/with G-CSF in a 14-day cycle in patients with advanced solid tumors. ASCO Annual Meeting Proceedings; 2008.

31. Macarulla T, Cervantes A, Elez E, Rodriguez-Braun E, Baselga J, Rosello S, et al. Phase I study of the selective Aurora A kinase inhibitor MLN8054 in patients with advanced solid tumors: safety, pharmacokinetics, and pharmacodynamics. Molecular cancer therapeutics. 2010;9(10):2844-52.

32. Katsha A, Belkhiri A, Goff L, El-Rifai W. Aurora kinase A in gastrointestinal cancers: time to target. Molecular Cancer. 2015;14(1):106.

33. First Multicenter, Randomized Phase 3 Study in Patients (Pts) With Relapsed/Refractory (R/R) Peripheral T-Cell Lymphoma (PTCL): Alisertib (MLN8237) Versus Investigator's Choice (LUMIERE trial; NCT01482962). Clinical advances in hematology \& oncology : H\&O. 2016;14(2 Suppl 1):12-3.

34. Dees EC, Infante JR, Cohen RB, O'Neil BH, Jones S, von Mehren M, et al. Phase 1 study of MLN8054, a selective inhibitor of Aurora A kinase in patients with advanced solid tumors. Cancer Chemotherapy and Pharmacology.

2011;67(4):945-54.

35. Sells TB, Chau R, Ecsedy JA, Gershman RE, Hoar K, Huck J, et al. MLN8054 and Alisertib (MLN8237): Discovery of Selective Oral Aurora A Inhibitors. ACS Medicinal Chemistry Letters. 2015;6(6):630-4.

36. Gabrielli B, Bokhari F, Ranall MV, Oo ZY, Stevenson AJ, Wang W, et al. Aurora A Is Critical for Survival in HPVTransformed Cervical Cancer. Molecular cancer therapeutics. 2015;14(12):2753-61.

37. Qi W, Spier C, Liu X, Agarwal A, Cooke LS, Persky DO, et al. Alisertib (MLN8237) an investigational agent suppresses Aurora A and B activity, inhibits proliferation, promotes endo-reduplication and induces apoptosis in T-NHL cell lines supporting its importance in PTCL treatment. Leukemia research. 2013;37(4):434-9.

38. Gorgun G, Calabrese E, Hideshima T, Ecsedy J, Perrone G, Mani M, et al. A novel Aurora-A kinase inhibitor MLN8237 induces cytotoxicity and cell-cycle arrest in multiple myeloma. Blood. 2010;115(25):5202-13.

39. Qi L, Zhang Y. Alisertib (MLN8237), a selective Aurora-A kinase inhibitor, induces apoptosis in human tongue squamous cell carcinoma cell both in vitro and in vivo. Tumour biology : the journal of the International Society for Oncodevelopmental Biology and Medicine. 2015;36(3):1797-802.

40. Zhou N, Singh K, Mir MC, Parker Y, Lindner D, Dreicer R, et al. The investigational Aurora kinase A inhibitor MLN8237 induces defects in cell viability and cell-cycle progression in malignant bladder cancer cells in vitro and in vivo. Clinical cancer research : an official journal of the American Association for Cancer Research. 2013;19(7):1717-28.

41. Carol H, Boehm I, Reynolds CP, Kang MH, Maris JM, Morton CL, et al. Efficacy and pharmacokinetic/pharmacodynamic evaluation of the Aurora kinase A inhibitor MLN8237 against preclinical models of pediatric cancer. Cancer Chemother Pharmacol. 2011;68(5):1291-304.

42. Tomita M, Mori N. Aurora A selective inhibitor MLN8237 suppresses the growth and survival of HTLV-1-infected T-cells in vitro. Cancer science. 2010;101(5):1204-11. 
43. Barr PM, Li H, Spier C, Mahadevan D, LeBlanc M, UI Haq M, et al. Phase II Intergroup Trial of Alisertib in Relapsed and Refractory Peripheral T-Cell Lymphoma and Transformed Mycosis Fungoides: SWOG 1108. Journal Of Clinical Oncology: Official Journal Of The American Society Of Clinical Oncology. 2015;33(21):2399-404.

44. Cervantes A, Elez E, Roda D, Ecsedy J, Macarulla T, Venkatakrishnan K, et al. Phase I pharmacokinetic/pharmacodynamic study of MLN8237, an investigational, oral, selective aurora a kinase inhibitor, in patients with advanced solid tumors. Clinical Cancer Research: An Official Journal Of The American Association For Cancer Research. 2012;18(17):4764-74.

45. Dees EC, Cohen RB, von Mehren M, Stinchcombe TE, Liu H, Venkatakrishnan K, et al. Phase I study of aurora A kinase inhibitor MLN8237 in advanced solid tumors: safety, pharmacokinetics, pharmacodynamics, and bioavailability of two oral formulations. Clinical Cancer Research: An Official Journal Of The American Association For Cancer Research. 2012;18(17):4775-84.

46. Dickson MA, Mahoney MR, Tap WD, D'Angelo SP, Keohan ML, Van Tine BA, et al. Phase II Study of MLN8237 (Alisertib) in Advanced/Metastatic Sarcoma. Annals of oncology : official journal of the European Society for Medical Oncology / ESMO. 2016.

47. Friedberg JW, Mahadevan D, Cebula E, Persky D, Lossos I, Agarwal AB, et al. Phase II study of alisertib, a selective Aurora A kinase inhibitor, in relapsed and refractory aggressive B- and T-cell non-Hodgkin lymphomas. Journal Of Clinical Oncology: Official Journal Of The American Society Of Clinical Oncology. 2014;32(1):44-50.

48. Goldberg SL, Fenaux P, Craig MD, Gyan E, Lister J, Kassis J, et al. An exploratory phase 2 study of investigational Aurora A kinase inhibitor alisertib (MLN8237) in acute myelogenous leukemia and myelodysplastic syndromes. Leukemia research reports. 2014;3(2):58-61.

49. Kelly KR, Shea TC, Goy A, Berdeja JG, Reeder CB, McDonagh KT, et al. Phase I study of MLN8237--investigational Aurora A kinase inhibitor--in relapsed/refractory multiple myeloma, non-Hodgkin lymphoma and chronic lymphocytic leukemia. Investigational New Drugs. 2014;32(3):489-99.

50. Matulonis UA, Sharma S, Ghamande S, Gordon MS, Del Prete SA, Ray-Coquard I, et al. Phase II study of MLN8237 (alisertib), an investigational Aurora A kinase inhibitor, in patients with platinum-resistant or -refractory epithelial ovarian, fallopian tube, or primary peritoneal carcinoma. Gynecologic Oncology. 2012;127(1):63-9.

51. Melichar B, Adenis A, Lockhart AC, Bennouna J, Dees EC, Kayaleh O, et al. Safety and activity of alisertib, an investigational aurora kinase $A$ inhibitor, in patients with breast cancer, small-cell lung cancer, non-small-cell lung cancer, head and neck squamous-cell carcinoma, and gastro-oesophageal adenocarcinoma: a five-arm phase 2 study. The Lancet Oncology. 2015;16(4):395-405.

52. Venkatakrishnan K, Kim TM, Lin C-C, Thye LS, Chng WJ, Ma B, et al. Phase 1 study of the investigational Aurora A kinase inhibitor alisertib (MLN8237) in East Asian cancer patients: pharmacokinetics and recommended phase 2 dose. Investigational New Drugs. 2015;33(4):942-53.

53. Quality Assessment Tool for Quantitative Studies Hamilton, ON: McMaster University: National Collaborating Centre for Methods and Tools; 2008 [Available from: http://www.nccmt.ca/registry/view/eng/14.html.

54. Dickson MA, Mahoney MR, Tap WD, D'Angelo SP, Keohan ML, Van Tine BA, et al. Phase II study of MLN8237 (Alisertib) in advanced/metastatic sarcoma. Annals of oncology : official journal of the European Society for Medical Oncology. 2016;27(10):1855-60.

55. Melichar B, Adenis A, Lockhart AC, Bennouna J, Dees EC, Kayaleh O, et al. Safety and activity of alisertib, an investigational aurora kinase $A$ inhibitor, in patients with breast cancer, small-cell lung cancer, non-small-cell lung cancer, head and neck squamous-cell carcinoma, and gastro-oesophageal adenocarcinoma: a five-arm phase 2 study. The Lancet Oncology. 2015;16(4):395-405.

56. Kelly KR, Shea TC, Goy A, Berdeja JG, Reeder CB, McDonagh KT, et al. Phase I study of MLN8237--investigational Aurora A kinase inhibitor--in relapsed/refractory multiple myeloma, non-Hodgkin lymphoma and chronic lymphocytic leukemia. Investigational new drugs. 2014;32(3):489-99.

57. Friedberg JW, Mahadevan D, Cebula E, Persky D, Lossos I, Agarwal AB, et al. Phase II study of alisertib, a selective Aurora A kinase inhibitor, in relapsed and refractory aggressive B- and T-cell non-Hodgkin lymphomas. Journal of clinical oncology : official journal of the American Society of Clinical Oncology. 2014;32(1):44-50.

58. Goldberg SL, Fenaux P, Craig MD, Gyan E, Lister J, Kassis J, et al. An exploratory phase 2 study of investigational Aurora A kinase inhibitor alisertib (MLN8237) in acute myelogenous leukemia and myelodysplastic syndromes. Leukemia Research Reports. 2014;3(2):58-61. 
59. Dees EC, Cohen RB, von Mehren M, Stinchcombe TE, Liu H, Venkatakrishnan K, et al. Phase I study of aurora A kinase inhibitor MLN8237 in advanced solid tumors: safety, pharmacokinetics, pharmacodynamics, and bioavailability of two oral formulations. Clinical cancer research : an official journal of the American Association for Cancer Research. 2012;18(17):4775-84.

60. Cervantes A, Elez E, Roda D, Ecsedy J, Macarulla T, Venkatakrishnan K, et al. Phase I

pharmacokinetic/pharmacodynamic study of MLN8237, an investigational, oral, selective aurora a kinase inhibitor, in patients with advanced solid tumors. Clinical cancer research : an official journal of the American Association for Cancer Research. 2012;18(17):4764-74.

61. Eisenhauer EA, Therasse P, Bogaerts J, Schwartz LH, Sargent D, Ford R, et al. New response evaluation criteria in solid tumours: revised RECIST guideline (version 1.1). European journal of cancer (Oxford, England : 1990). 2009;45(2):228-47.

62. Therasse P, Arbuck SG, Eisenhauer EA, Wanders J, Kaplan RS, Rubinstein L, et al. New guidelines to evaluate the response to treatment in solid tumors. European Organization for Research and Treatment of Cancer, National Cancer Institute of the United States, National Cancer Institute of Canada. Journal of the National Cancer Institute. 2000;92(3):205-16.

63. Chatelut E, Delord JP, Canal P. Toxicity patterns of cytotoxic drugs. Invest New Drugs. 2003;21(2):141-8.

64. Yang J, Wray NR, Visscher PM. Comparing apples and oranges: equating the power of case-control and quantitative trait association studies. Genetic epidemiology. 2010;34(3):254-7.

65. Weinstein IB, Begemann M, Zhou P, Han EK, Sgambato A, Doki Y, et al. Disorders in cell circuitry associated with multistage carcinogenesis: exploitable targets for cancer prevention and therapy. Clinical cancer research : an official journal of the American Association for Cancer Research. 1997;3(12 Pt 2):2696-702.

66. Torti $D$, Trusolino L. Oncogene addiction as a foundational rationale for targeted anti-cancer therapy: promises and perils. EMBO Molecular Medicine. 2011;3(11):623-36.

67. Wolinsky JB, Colson YL, Grinstaff MW. Local Drug Delivery Strategies for Cancer Treatment: Gels, Nanoparticles, Polymeric Films, Rods, and Wafers. Journal of controlled release : official journal of the Controlled Release Society. 2012;159(1):10.1016/j.jconrel.2011.11.031. 